\title{
Determination of 3-Mercaptopropionic Acid by HPLC: A Sensitive Method for Environmental Applications
}

P. Salgado ${ }^{1 *}$, T. Visnevschi-Necrasov ${ }^{1}$, R.P. Kiene ${ }^{2}$, I. Azevedo ${ }^{1}$, A.C.S. Rocha ${ }^{1}$, C.M.R. Almeida $^{1}$, C. Magalhães ${ }^{1}$

${ }^{1}$ CIMAR/CIIMAR - Centre of Marine and Environmental Research, University of Porto; Rua dos Bragas, $n^{\circ} 289$, 4050-123 Porto, Portugal.

${ }^{2}$ Department of Marine Sciences, University of South Alabama; LSCB 25, Mobile, Alabama, USA 36688 and Dauphin Island Sea Lab, Dauphin Island, Alabama 36528, USA.

${ }^{*}$ Corresponding author: EcoBioTec Laboratory, Interdisciplinary Centre of Marine and Environmental Research (CIIMAR/CIMAR), University of Porto, Rua dos Bragas 289, P 4050123 Porto, Portugal.

*E-mail: psalgado@ciimar.up.pt; Tel.: 00351-223401854 


\section{Abstract}

The organic sulfur compound 3-mercaptopropionic acid (3-MPA) is an important thiol intermediate in organic sulfur metabolism in natural environments. It is generated during degradation of sulfur-containing amino acids (e.g. methionine) and from demethylation of dimethylsulfoniopropionate (DMSP). This pathway is an alternative enzymatic process in the DMSP catabolism that routes sulfur away from the climatically-active dimethyl sulfide (DMS). 3MPA detection and subsequent quantification in different matrices is difficult due to its extreme reactivity. We therefore developed a sensitive method for determination of 3-MPA based on precolumn derivatization with monobromobimane and analysis by high- performance liquid chromatography (HPLC) with fluorescence detection. This methodology was first tested with 3MPA standards under low (0.005-0.2 $\left.\mathrm{molL}^{-1}\right)$ and high $\left(1-25 \mu \mathrm{molL}^{-1}\right)$ concentrations. For the optimization of the reaction, $\mathrm{CHES}$ and, alternatively, Tris- $\mathrm{HCl}$ buffers were evaluated in the derivatization step, with $\mathrm{Tris}-\mathrm{HCl}$ showing more effective separation of thiol derivatives and a better 3-MPA peak shape. The detection limit was $4.3 \mathrm{nmolL}^{-1}$ with a $10 \mu \mathrm{L}$ sample injection, and mean recoveries of 3 -MPA ranged from $97-105 \%$ in estuarine waters with different salinities(0.17 and $35.9 \mathrm{ppt})$. The linearity $(r>0.99)$ and repeatability of detectorresponse, with intra- and inter-day precision (\% CV) of $2.68-7.01 \%$ and $4.86-12.5 \%$, respectively, confirmed the reliability of the method. Previous 3-MPA analytical methods required immediate analysis due to unstable derivatives, but in this method we achieved high stability of the derivatized samples when stored at $4^{\circ} \mathrm{C}$, with only a $3-5 \%$ loss after more than one year of storage. This method was successfully applied to measure 3-MPA concentrations and rates of 3-MPA production in a variety of intertidal estuarine sediment slurries. Dissolved 3-MPA concentrations in these sedimentslurries varied between 2 and $237 \mu \mathrm{molL}^{-1}$ and, 3-MPA net fluxes ranged in wet sediments between $-3.6 \pm 1.7$ and $30 \pm 5 \mu \mathrm{molL}^{-1} \mathrm{~g}^{-1} \mathrm{~h}^{-1}$. Thus, the application of this optimized methodology showed an efficient performance for measuring 3-MPA in environmental 
samples, with astraightforward sample derivatization and a simple analysis of stable 3-MPA derivatives.

Keywords: 3-mercaptopropionic acid (3-MPA), High-Performance Liquid Chromatography (HPLC), Monobromobimane, Thiols. 


\section{Introduction}

Low molecular weight thiols are important because of their biological turnover in natural environments. In fact, they have a fundamental role in sulfur biogeochemistry,being major intermediates inthe processes involved inmicrobial organic sulfur transformations [1-5]. Additionally, they are an important group of compounds due to their unique role in medicine, food, pharmaceutical and aroma industries [6-8]. Together, these characteristics have led to considerable interest in thiolic compounds such as cysteine (CySH) and glutathione(GSH) which have critical functions in physiological processes in a variety of living organisms, ranging from microbes to humans [9-12]. As a result, considerable effort has gone into developing accurate and sensitive methodologies to extract and measure cysteine and glutathione in a variety of sample matrices[13-18] or in the determination of several thiol drugs $[9,19]$. However, less attention has been given to other low-molecular-weight hydrophilic thiols such as 3mercaptopropionic acid ( $\left.\mathrm{HSCH}_{2} \mathrm{CH}_{2} \mathrm{CO}_{2} \mathrm{H} ; 3-\mathrm{MPA}\right)$ which is found in significant concentrations in natural aquatic environments [20-23].

In this study we focused on developing a sensitive and accurate method to measure 3-MPA. This thiol is a major natural organic sulfur compound (thiol) produced during microbial decomposition of sulfur-containing amino acids like methionine and homocysteine $[20,21,24,25]$. In natural environments, 3-MPA can also be formed duringmicrobial decomposition of the osmolyte dimethylsulfoniopropionate (DMSP), an important carbon and sulfur source to marine bacterial communities. 3-MPA is produced from DMSP through two successive demethylations $[20,26]$. Demethylation of DMSP is an alternative pathway to the so-called cleavage pathway which produces dimethyl sulfide (DMS), a sulfur gas with a potential role in climate [27]. Production of 3-MPA has been demonstrated to occur in aerobic bacterial cultures and anoxic sediments $[1,20,25,28,29]$ from 3-methiolpropionate (MMPA), which is the first product during the double demethylation of DMSP $[26,30]$. Since 3-MPA is a central compound in natural 
organic sulfur geochemistry $[4,25,28]$, its determination remains important in biogeochemical and environmental studies. However, only a few methods have been developed to quantify it in different matrices, which limits our knowledge of 3-MPA transformations and interactions in natural environments. Previously described methods for thiol analysis in biological samples were based on o-phthalaldehyde (OPA) for pre- or post-column derivatizations in HPLC, in which thiols react to form fluorescent derivatives [e.g. 31-33]. While sensitive, the OPA derivatization method has several disadvantages, namely therapid degradation of derivatives. Also, since thiols are highly susceptible to oxidation with molecular oxygen, samples must be processed immediately $[2,20]$, and this poses practical limitations with the OPA method because the derivatives are unstable. Recently, a new microchip capillary electrophoresis (CE)-based method has been developed for the determination of thiols (e.g. 2-MPA) in cosmetics (depilatory cream and wave lotions) after their derivatization with the fluorogenic reagent ammonium-7fluorobenzo-2-oxa-1,3-diazole-4-sulfonate (SBD-F) [17]. This work reported that microchip CE analysis requires small amounts of sample and reagents and that separation times can be reduced compared to conventional methods. Nevertheless, the detection limit is relatively high $\left(2 \mu \mathrm{molL}^{-1}\right)$ which becomes limiting to quantify 3-MPA in natural environments with typical concentrations ranging from $\mathrm{nmolL}^{-1}$ to $\mu \mathrm{mol} \mathrm{L^{-1 }}$ levels. In fact, previous analytical methods for measuring 3-MPA have already established alimit of detection(LOD) at ultratrace levels for the thiol determinations $[2,25,32]$.

The methodology used in the present study was based on the Newton and Fahey [34] derivatization method with monobromobimane $(\mathrm{MBBr})$ followed by high- performance liquid chromatography (HPLC) analysis, a method previously used for the determination of biothiols (CySH and GSH) and thiol drugs (cysteamine, penicillamine and mercaptopropionylglycine). The method was optimized for a quick sample analysis, long-term storage of derivatized samples and allowing the measurement of 3-MPA at nmol $\mathrm{L}^{-1}$ concentrations. 


\section{Materials and Methods}

\subsection{Chemicals and reagents}

The 3-mercaptopropionic acid (3-MPA) used had a purity of $\geq 99 \%$. The remaining reagents, 6 mmol L-1 dithiothreitol (DTT, Fluka), $0.2 \mathrm{molL}^{-1}$ 2-(cyclohexylamino) ethanesulfonic acid (CHES) and $1 \mathrm{molL}^{-1}$ Tris-(hydroxymethyl)-aminomethane (Tris-HCl) ultrapure grade $\geq 99.9 \%$, were prepared in pure HPLC grade water. The derivatizing reagent solution, $30 \mathrm{mmolL}^{-1}$ monobromobimane (MBBr), was prepared in $100 \%$ of HPLC grade methanol. Pure HPLC grade water, analytical grade acetic acid, 3-MPA, MBBr, CHES and methanol were obtained from Sigma-Aldrich (St. Louis, MO, USA).

\section{2. . Method development}

\subsubsection{HPLC conditions}

Chromatographic analyses were performed with a Shimadzu LC-20AD HPLC (Analytical and Measuring Instruments Division, Kyoto, Japan). This high-performance liquid chromatograph (HPLC) was equipped with twoLC-10AD pumps, SIL-20ACHT automatic sampler with an injection-volume setting range of 0.1 to $100 \mu \mathrm{L}$ and a CTO-10ASvp column oven. Detection was performed with a Shimadzu high pressure RF-20A XS fluorescence detector at excitation of $\lambda$ $380 \mathrm{~nm}$ and emission of $\lambda 480 \mathrm{~nm}$. The chromatographic separation of the compoundswas achieved with a mediterranea $\operatorname{sea}_{18} 5 \mu \mathrm{m}(25 \mathrm{~cm} \times 0.46 \mathrm{~cm})$ column (Teknokroma, Spain) operating at $20^{\circ} \mathrm{C}$. The eluent consisted of two methanol-aqueous (pure water) mobile phases (mobile phase A was 2:98 (v/v) and mobile phase B was 90:10 (v/v)), at a flow rate of 0.9 $\mathrm{mLmin}^{-1}$, with a linear gradient as follows: 1 minute $7 \% \mathrm{~B}, 5$ minutes $30 \% \mathrm{~B}, 35$ minutes $60 \% \mathrm{~B}$, 35.01 minutes 7\% B (mobile phase B as default), maintaining these conditions for 10 
minutesand returning to the initial conditions. Data were analyzed using LCsolution Version 1.25 Software (Shimadzu, Japan).

\subsubsection{Method validation}

Our analytical method was validated by a set of verification parameters such as linearity, accuracy, precision, recovery, sensitivity and stability, in order to corroborate the reliability of obtained results. In addition, measurements of the analyte were also performedin estuarine waters [35].

The linearity of the method was tested using an external standard calibration with different concentration levels of 3-MPA standard solutions. A total of six and five standards were used for high $\left(1,5,10,15,20\right.$ and $\left.25 \mu_{\mathrm{molL}}{ }^{-1}\right)$ and low $\left(0.005,0.01,0.05,0.1\right.$ and $\left.0.2 \mu \mathrm{molL}^{-1}\right)$ concentration calibration curves, respectively. Each derivatized standard was injected at a $10 \mu \mathrm{L}$ volume into theHPLC in duplicate, in order to account for the inherent HPLC variability between different runs. The calibration curve, the relationship between the known concentration and detector response (peak area) of the analyte, was determined by a linear regression.

Accuracy (Bias \%) was evaluated by determination of 3-MPA recoveries from spiked estuarine water samples (see below) and spiked HPLC grade water. The accuracy with different high and low concentrations was estimated based on Causon [36]: Bias $(\%)=[($ measured value - true value) / true value] $x$ 100. Recovery of 3-MPA was calculated by comparing the detector response of added 3-MPA at four fortification levels $\left(1 \mu \mathrm{molL}^{-1}, 5 \mu \mathrm{molL}^{-1}, 10 \mu \mathrm{molL}^{-1}\right.$ and 20 $\mu_{\mathrm{molL}}{ }^{-1}$ ) to HPLC grade water (standard solutions) and to environmental estuarine waters with different salinities (0.17 and 35.85 ppt) according to Cassiano et al. [37]. To calculate the recovery values, the contribution of 3-MPA in the unspiked "blank" sample was subtracted from the corresponding value obtained in each spiked sample. 
Precision of the method was evaluated through repeatability of intra- and inter-day assays. The former was conducted by measuring five replicates of different concentrations (1, 10 and 25 $\mu \mathrm{mol} \mathrm{L}^{-1}$ ) in the same day and the latter by repeating assays on six different days with two replicates at each of six different fortification levels $\left(1-25 \mu \mathrm{mol} \mathrm{L}{ }^{-1}\right)$.

This parameter is expressed as the coefficient of variation $(\mathrm{CV} \%)$ : CV $(\%)=$ (standard deviation/mean) x 100. Based on Causon [36], both precision and accuracy measures should be within $\pm 15 \%$ for a reliable method.

Sensitivity of the method was assessed through the LODand limit of quantification (LOQ). LOD is defined as the lowest concentration of an analyte in a sample that the method can detect (and not necessarily quantify). Since the analytical method is based on a linear calibration the LOD was calculated according to the formula LOD $=3^{*} S D / S$, where SD represents the standard deviation of the detector response and $S$ the slope of the regression line [38]. LOQ is defined as the lowest concentration of the analyte of interest in a sample that can be quantified with acceptable precision and accuracy and it was calculated again based on the standard deviation of the detector response (SD) and the slope of the calibration curve (S) according to the formula: $L O Q=10^{*} S D / S$ [38]. The standard deviation of the detector response can be determined based on the standard deviation of $y$-intercepts of the regression line.

\subsection{Standards}

3-MPA primary standard solution was prepared in $10 \mathrm{mmolL}^{-1}$ concentration by weighing a precise compound mass and diluting it in a precise volume of HPLC grade water. HPLC grade water used for the standard was previously purged with $\mathrm{N}_{2}$ for 20 minutes to minimize 3-MPA oxidation. The primary standard solution at $10 \mathrm{mmolL}^{-1}$ was then diluted into a $0.1 \mathrm{mmolL}^{-1}$ secondary standard and into a $0.001 \mathrm{mmolL}^{-1}$ tertiary standard solution to achieve the different 
concentrations. All standardsolutions, including the primary standard, were prepared daily for each of the method validationprocedures.

\subsection{Sample derivatization}

The bimane derivatization method [14-16,34] was used to stabilize 3-MPA, with some modifications. Briefly, to $120 \mu \mathrm{L}$ of sample, $180 \mu \mathrm{L}$ of $0.2 \mathrm{~mol} \mathrm{~L}^{-1} \mathrm{CHES}(\mathrm{pH} 9.3)$ or $1 \mathrm{molL}^{-1}$ Tris$\mathrm{HCl}(\mathrm{pH} 7.5)$ buffer was added and $30 \mu \mathrm{l}$ of $6 \mathrm{mmol} \mathrm{L}^{-1} \mathrm{DTT}$ to reduce disulfides. Inclusion of the DTT in the reaction mixture will ensure that the total 3-MPA in the sample, including any disulfide forms of 3-MPA, will be included in the measurement. Samples were then incubated for 1 hour on ice. After reduction of disulfides $10 \mu \mathrm{L}$ of $30 \mathrm{mmolL}^{-1} \mathrm{MBBr}$ was added to the sample and the mixture incubated for 15 minutes at room temperature in the dark. The bimane conjugate was stabilized by adding $250 \mu \mathrm{L}$ of $5 \%$ acetic acid and samples were processed on the HPLC within a period of 24 hours, unless otherwise stated. Stability of 3-MPA derivatives at $4^{\circ} \mathrm{C}$ was evaluated for different $\left(5 \mu \mathrm{molL}^{-1}, 10 \mu \mathrm{molL}^{-1}\right.$ and $\left.25 \mu \mathrm{molL}^{-1}\right)$ concentrations in successive HPLC runs of the same samples measured at different times (1 day, 2 days, 1 week, 2 weeks, 2 months and more than 1 year after the derivatization procedure).

\subsection{Environmental samples}

3-MPA accumulation rates were measured in environmental samples representative of the intertidal Douro River Estuary: fine sand, sandy and muddy sediments and rocky biofilms. Rates were measured in slurries consisting of a mix of $5 \mathrm{~g}$ of surficial estuarine intertidal sediment or scraped rocky biofilm $(\sim 1 \mathrm{~g})$ and $10 \mathrm{~mL}$ of estuarine overlying water in $30 \mathrm{~mL}$ serum bottles $[39,40]$. Serum bottles were hermetically sealed with a Teflon-faced rubber stopper and 
aluminum crimp seals. Then, a set of triplicate slurries for each type of sediment/biofilm was incubated in the dark, under oxic (air headspace) conditions and a separate set of time zero samples was subjected immediately to derivatization as previously described in Section 2.4 Sample Derivatization. At time zero and after an incubation of 4 hours, at constant temperature $\left(20^{\circ} \mathrm{C}\right)$ with rotary shaking $(80 \mathrm{rpm}), 1 \mathrm{~mL}$ of each slurry was collected into a microtube and centrifuged at $13000 \times \mathrm{g}$ for 1 minute according to [2]. Sub-samples (120 $\mu \mathrm{L})$ of clear supernatant were immediately derivatized following the same abovementioned procedure for 3MPA standards. At each of these environments, estuarine water from the Douro Estuary, used also to validate the optimized methodology, was collected and stored in acid-cleaned polyethylene bottles. In the laboratory, estuarine water of different salinities was immediately filtered (0.2 $\mu \mathrm{m}$, membrane filters) and later the 3-MPA concentrations measured in centrifuged samples as described above for 3-MPA standards.All measurements were carried out on the day of sampling, together with the respective standard solutions.

\section{Results and discussion}

\subsection{Method optimization}

In this study we based our optimization on the previous HPLC methodology developed by Newton and Fahey [34], which was designed as a sensitive method for low molecular weight biothiols analysis (e.g. CySH, GSH, cysteinylglycine, $y$-glutamylcysteine). That derivatization method used two comparable bromobimane reagents that interact and label the thiol group, monobromobimane $(\mathrm{MBBr})$ and sulfonylbenzoyloxybromobimane (SBBr). The bromobimanes are useful reagents because they produce fluorescent derivatives and help prevent oxidative loss of thiols during sample preparation and analysis [41]. The kinetics of the reaction of both $\mathrm{SBBr}$ and $\mathrm{MBBr}$ fluorescent labeling agents was shown to be similar with any thiol $[34,42]$. 
However, our choice for $\mathrm{MBBr}$ relied on the high fluorescent derivative yield, the fastest derivatization process and, also, the derivatives stability $[43,44]$. The selection of the remaining reagents to our analytical method was based onthe protocols ofKoprivova et al. [14]. The low molecular massthiol analysis was optimized by initially buffering the 3-MPA standards or environmental samples with 0.2 molL $^{-1}$ CHES ( $\mathrm{pH}$ 9.3) and consecutively adding DTT, which reduces disulfides due to its low redox potential and does not interfere with the analytical procedure [45]. However, the use of CHES ( $\mathrm{pH} 9.3)$ in our derivatization experiments resulted in an unfavorable separation of the peak for the thiol 3-MPA, due to the appearance of another extraneous derivatization peak just beside the main compound (Fig. 1a). The substitution of CHES ( $\mathrm{pH}$ 9.3) by $1 \mathrm{molL}^{-1}$ Tris- $\mathrm{HCl}(\mathrm{pH}$ 7.5) resulted in a separation improvement and resolution of 3-MPA peak shape with a 25.8 minute retention time (Fig. $1 \mathrm{~b}$ ). Tris- $\mathrm{HCl}$ is a common buffer in HPLC assays and was previously used in other thiol derivatizations (e.g. CySH, GSH) with good separation and peak shapes [46-48].

A series of experiments were then performed to evaluate our method in terms of linearity, accuracy, precision, recovery, sensitivity, stability and its capacity to detect 3-MPA in environmental samples.

\subsection{Method assessment}

\subsubsection{Linearity}

Our results revealed that the area of the chromatographic peaks was proportional to the concentration of 3-MPA in both high (1-25 $\mu \mathrm{mol} \mathrm{L}{ }^{-1}$, Fig. $\left.2 a\right)$ and low ranges $\left(0.005-0.2 \mu \mathrm{mol} \mathrm{L}^{-}\right.$

${ }^{1}$, Fig. 2b). Calibration curves were linear, with correlation coefficients of $r>0.99(p<0.001)$ for the high range samples and $r=0.99$ for the low range samples.

\subsubsection{Precision and Accuracy}


For intra-dayprecision, derivatization was performed at three fortification levelsin HPLC-grade waterand each was repeated five times independently in a single day. Precision of the intra-day measurements was $7.01,2.68$ and $3.01 \%$ for $1 \mu \mathrm{molL}^{-1}, 10 \mu \mathrm{molL}^{-1}$ and $25 \mu \mathrm{molL}^{-1} 3-\mathrm{MPA}$ concentrations, respectively.

For inter-dayprecision, derivatization was carried out withsix fortification levels in HPLC grade water $\left(1 \mu \mathrm{molL}^{-1}, 5 \mu \mathrm{molL}^{-1}, 10 \mu \mathrm{molL}^{-1}, 15 \mu \mathrm{molL}^{-1}, 20 \mu \mathrm{molL}^{-1}, 25 \mu \mathrm{molL}^{-1}\right)$, repeated on six different days with precision varying between4.86 and12.5\% (Table 1).Accuracy for spiked HPLC grade water samples varied between -5.00 and $7.70 \%$ (Table 1). Based on these results, we conclude that the precision and accuracy of the method is acceptable, based on \%CV and $\%$ Bias < 15\% (Table 1).

Regarding spiked estuarine water samples, recoveries of 3-MPA were in the range of $98-105 \%$ in the low salinity estuarine samples $(0.17 \mathrm{ppt})$ and slightly lower $(97-102 \%)$ in the $35.85 \mathrm{ppt}$ samples (Table 2). Because the recovery is close to $100 \%$ which maximizes the sensitivity of the method [36], we conclude that the optimized method represents a reliable procedure to measure 3-MPA in estuarine water samples within a high range of salinities.Accuracy for estuarine water samples was identical to that observed for spiked HPLC grade water samples ($4.60 \%$ to $12.6 \%)$.

\subsubsection{Detection and quantification limits}

The determination of LOD and LOQ of our method was based on the Miller and Miller [38] calculation by using the data from the regression line of low 3-MPA standards $(0.005-0.2$ $\mu \mathrm{molL}{ }^{-1}$ ). Hence, the LOD corresponded to $4.3 \mathrm{nmolL}^{-1}$ and the LOQ to $14.5 \mathrm{nmolL}^{-1}(r>0.99)$, values similar to those in the literature $[2,25,32]$ but with a much simpler procedure. Our 
methodological approach also has the advantage that derivatized samples can be stored for later analysis (see below).

\subsubsection{Storage stability}

Storage stability of derivatized samples was evaluated for different standard concentrations (5 $\mu \mathrm{mol} \mathrm{L} \mathrm{L}^{-1}, 10 \mu \mathrm{mol} \mathrm{L} \mathrm{L}^{-1}$ and $25 \mu \mathrm{mol} \mathrm{L^{-1 } )}$ in order to estimate the period during which the derivatized samples could be stored at $4^{\circ} \mathrm{C}$ before being analyzed without appreciable changes in 3-MPA concentrations. 3-MPA concentrations in HPLC grade water spiked at three fortification levels were measured at day 1, day 2, after one and two weeks, after two months and after one year of storage. Results demonstrated high stability of 3-MPA concentrations in derivatized samples stored at $4{ }^{\circ} \mathrm{C}$ for all storage periods tested. After 2 months of storage, the

$5 \mu \mathrm{mol} \mathrm{L}{ }^{-1} 3-\mathrm{MPA}$ standard was at $96 \%$ of the day 1 value, and the 10 and $25 \mu \mathrm{mol} \mathrm{L}^{-1} 3-\mathrm{MPA}$ standards had $108 \%$ of the Day 1 values (Table 3 ). After one year of storage, the three different 3-MPA standards were at $95-97 \%$ of the Day 1 values (Table 3). According to Causon [36], this qualifies our sample derivatives as stable, since the deviation was below $15 \%$. This stability is an additional validation for the present method and offers the significant advantage that derivatized samples can be stored at $4{ }^{\circ} \mathrm{C}$ up to one year with minimal losses of 3-MPA.

\subsection{Determination of 3-MPA content in environmental samples}

Our method enabled the measurement of dissolved 3-MPA in slurries of estuarine sediments and rocky biofilms under oxic conditions. Results revealed that dissolved 3-MPA concentrations varied between $2 \mu \mathrm{molL}^{-1}$ and $237 \mu \mathrm{molL}^{-1}$, in slurries of sediments and rocky biofilms collected in the Douro River estuary, Portugal. We were also able to use our method to measure net flux 
rates of 3-MPA in the same environmental samples, with values ranging between $-3.6 \pm 1.7 \mu \mathrm{mol}$ $\mathrm{L}^{-1} \mathrm{~g}^{-1} \mathrm{~h}^{-1}$ (i.e. net consumption of 3-MPA) and $+30 \pm 5 \mu \mathrm{mol} \mathrm{L}^{-1} \mathrm{~g}^{-1} \mathrm{~h}^{-1}$ in muddy and sandy sediments and in rocky biofilms, respectively (Fig. 3). Therefore, our method allows the sensitive quantification of the concentration and rates of production/consumption of the thiol 3MPA in several environmentally-relevant samples.

\section{Conclusions}

In this study we developed and qualified a methodology for determination of 3-MPA in environmental samples by HPLC, using monobromobimane as a derivatizing agent and an appropriate buffer (Tris- $\mathrm{HCl}$ ) that provided good chromatographic peak separation of the derivative. This method represents a reliable technique for measuring the thiol 3-MPA in estuarine sediment samples, requiring only small amounts of sample. The sampling and derivatization steps are simple and rapid, taking only $\sim 1.5$ hours. Also, the optimized derivatization allowed sample storage for at least one year with good recoveries ( 100\%), a considerable advantage compared with other 3-MPA methodologies. Furthermore, the repeatability of the standards and the high recovery of 3-MPA in spiked estuarine water samples with a significant range of salinities confirmed an overall accurate and precise determination of the thiol 3-MPA, reflecting the integrity of method. In addition, low LODs were obtained allowing the successful determination of net 3-MPA production rates in natural sediment samples. Nevertheless, future research will be needed to improve the technique for application to other types of samples and environments, such the marine water column, where an even lower LOD of 3-MPA is necessary. 
Acknowledgments

This study was funded by the Portuguese Science and Technology Foundation (FCT) through a PosDoc fellowship (SFRH/BPD/76989/2011) and research grants (PTDC/MAR/098914/2008; PTDC/AAC-AMB/113973/2009) to C. Magalhães. This research was partially supported by the European Regional Development Fund (ERDF) through the COMPETE - Operational Competitiveness Program.R. Kiene acknowledges support from the NSF Dimensions of Biodiversity program (grant OCE 1342699).

References

[1] K. Mopper, F. Taylor Barrie, Organic Marine Geochemistry, ACS Symp. Ser., (1986) p. 324.

[2] R.P. Kiene, Biogeochemistry 13 (1991) 117.

[3] R.P. Kiene, L.J. Linn, J.A. Bruton, J. Sea Res. 43 (2000) 209.

[4] M.A. Vairavamurthy, W.S. Goldenberg, S. Ouyang, S. Khalid, Mar. Chem. 70 (2000) 181.

[5] X.H. Ju, S. Tang, Y. Jia, J. Guo, Y. Ding, Z. Song, Y. Zhao, J. Chromatogr. B 879 (2011) 1717.

[6] A. de Graaf-Hess, F. Trijbels, H. Blom, Clin. Chem. 45 (1999) 2224.

[7] J. Seligman, G.L. Newton, R.C. Fahey, R. Shalgi, N.S. Kosower, J. Androl. 26 (2005) 629.

[8] P.D. Tzanavaras, T.D. Karakosta, J. Pharmaceut. Biomed. 54 (2011) 882.

[9] G.L. Newton, C.A. Bewley, T.J. Dwyer, R. Horn, Y. Aharonowitz, G. Cohen, J. Davies, D.J. Faulkner, R.C. Fahey, Eur. J. Biochem. 230 (1995) 821.

[10] R. Minocha, P. Thangavel, O.P. Dhankher, S. Long, J. Chromatogr. A 1207 (2008) 72. 
[11] A. Del Corso, P. Giuseppe Vilardo, M. Cappiello, I. Cecconi, M. Dal Monte, D. Barsacchi, U. Mura, Arch. Biochem. Biophys. 397 (2002) 392.

[12] M. Özyürek, S. Baki, N. Güngör, S.E. Çelik, K. Güçlü, R. Apak, Anal. Chim. Acta 750 (2012) 173.

[13] S.G. Fan, J.P. Zhou, H. Xu, J.S. Han, Brain Res. 337 (1985) 184.

[14] A. Koprivova, A.J. Meyer, G. Schween, C. Herschbach, R. Reski, S. Kopriva, J. Biol. Chem. 277 (2002) 32195.

[15] A. Jarosz-Wilkołazka, M. Grąz, B. Braha, S. Menge, D. Schlosser, G.-J. Krauss, Biometals 19 (2006) 39.

[16] M. Rother, G.-J. Krauss, G. Grass, D. Wesenberg, Plant, Cell Environ. 29 (2006) 1801.

[17] T. Revermann, S. Götz, U. Karst, Electrophoresis 28 (2007) 1154.

[18] M. Sun, B. Ding, J. Yu, Y.-L. Hsieh, G. Sun, Sensor. Actuat. B: Chem. 161 (2012) 322.

[19] K. Kuśmierek, G. Chwatko, R. Głowacki, E. Bald, J. Chromatogr. B 877 (2009) 3300.

[20] R.P. Kiene, B.F. Taylor, Nature 332 (1988) 148.

[21] R.P. Kiene, K.D. Malloy, B.F. Taylor, Appl. Environ. Microbiol. 56 (1990) 156.

[22] R. Al-Farawati, C.M.G. van den Berg, Environ. Sci. Technol. 35 (2001) 1902.

[23] J. Zhang, F. Wang, J.D. House, B. Page, Limnol. Oceanogr. 49 (2004) 2276.

[24] H. Hu, S.E. Mylon, G. Benoit, Limnol. Oceanogr. 51 (2006) 2763.

[25] R.P. Kiene, B.F. Taylor, Appl. Environ. Microbiol. 54 (1988) 2208.

[26] P.T. Visscher, M.R. Diaz, B.F. Taylor, Mar. Ecol.Prog. Ser. 89 (1992) 293.

[27] R.J. Charlson, J.E. Lovelock, M.O. Andreae, S.G. Warren, Nature 326 (1987) 655.

[28] A. Vairavamurthy, K. Mopper, Nature 329 (1987) 623.

[29] P.T. Visscher, B.F. Taylor, Appl. Environ. Microbiol. 60 (1994) 4617.

[30] B.F. Taylor, D.C. Gilchrist, Appl. Environ. Microbiol. 57 (1991) 3581.

[31] H. Nakamura, Z. Tamura, Anal. Chem. 53 (1981) 2190.

[32] K. Mopper, D. Delmas, Anal. Chem. 56 (1984) 2557. 
[33] H. Frister, H. Meisel, E. Schlimme, Fresen. Z. Anal. Chem. 330 (1988) 631.

[34] G.L. Newton, R.C. Fahey, Methods Enzymol.251(1995) 148.

[35] FDA, in: F.a.D.A. U.S. Department of Health and Human Services, Center for Drug Evaluation and Research (CDER), Center for Veterinary Medicine (CVM) (Ed.), Washington, DC, 2001.

[36] R. Causon, J. Chromatogr. B: Biomed. Sci. Appl. 689 (1997) 175.

[37] N.M.B. Cassiano, J. C.; Martins, I. R. R.; Oliveira, R. V.; Cass, Q. B., Quim. Nova 32 (2009) 1021.

[38] J.N. Miller, J.C. Miller, Statistics and chemometrics for analytical chemistry, Pearson Education, 2005.

[39] C. Magalhães, R.P. Kiene, A. Buchan, A. Machado, W.J. Wiebe, A.A. Bordalo, Environ. Microbiol. Rep. 3 (2011) 308.

[40] C. Magalhães, R.P. Kiene, A. Buchan, A. Machado, C. Teixeira, W.J. Wiebe, A.A. Bordalo, Biogeochemistry 107 (2012) 393.

[41] N.S. Kosower, E.M. Kosower, Methods Enzymol. Academic Press 143 (1987) 76.

[42] G.L. Newton, J.A. Aguilera, R.C. Fahey, J.F. Ward, A.E. Radkowsky, E.M. Kosower, Anal. Biochem. 201 (1992) 30.

[43] R.C. Fahey, G.L. Newton, Methods Enzymol.143 (1987) 85.

[44] F.E.C. Sneller, L.M. van Heerwaarden, P.L.M. Koevoets, R. Vooijs, H. Schat, J.A.C. Verkleij, J. Agric. Food Chem. 48 (2000) 4014.

[45] W.W. Cleland, Biochemistry 3 (1964) 480.

[46] N. Ercal, P. Yang, N. Aykin, J. Chromatogr. B: Biomed. Sci. Appl. 753 (2001) 287.

[47] A.I.G. Lima, S.I.A. Pereira, E.M. de Almeida Paula Figueira, G.C.N. Caldeira, H.D.Q. de Matos Caldeira, Environ. Exp. Bot. 55 (2006) 149.

[48] S. Hoff, F.H. Larsen, M.L. Andersen, M.N. Lund, Analyst 138 (2013) 2096.

[49] R.C. Fahey, G.L. Newton, R. Dorian, E.M. Kosower, Anal. Biochem. 111 (1981) 357. 


\section{Table captions}

Table 1 - Method validation parameters assessed by analysis of HPLC grade water samples spiked with a 3-MPA standard solution.

Table 2 - Average of recoveries and Relative Standard Deviation (RSDs) for two estuarine waters with different salinity, spiked with suitable volumes of a 3-MPA standard solution.

Table 3 - Recoveries (\%) of 3-MPA from spiked HPLC grade water as a function of stability storage period.

Figure captions

Figure 1 - HPLC chromatogram of 5 and $10 \mu \mathrm{mol} \mathrm{L}^{-1}$ 3-MPA standard solution resulting from the Bimane Derivatization Method with (a) CHES buffer, $\mathrm{pH}=9.3\left(0.2 \mathrm{~mol} \mathrm{~L}^{-1}\right)$ and (b) Tris- $\mathrm{HCl}$ buffer, $\mathrm{pH}=7.5\left(1 \mathrm{~mol} \mathrm{~L}^{-1}\right)$.

Figure 2 - Calibration curves obtained byHPLC of (a) high $\left(1 \mu \mathrm{mol} \mathrm{L} \mathrm{L}^{-1}, 5 \mu \mathrm{mol} \mathrm{L}{ }^{-1}, 10 \mu \mathrm{mol} \mathrm{L}{ }^{-1}\right.$, $\left.15 \mu \mathrm{mol} \mathrm{L} \mathrm{L}^{-1}, 20 \mu \mathrm{mol} \mathrm{L}{ }^{-1}, 25 \mu \mathrm{mol} \mathrm{L}{ }^{-1}\right)$ and (b) low $\left(0.005 \mu \mathrm{mol} \mathrm{L}-1,0.01 \mu \mathrm{mol} \mathrm{L}^{-1}, 0.05 \mu \mathrm{mol} \mathrm{L}^{-1}\right.$, $0.10 \mu \mathrm{mol} \mathrm{L}^{-1}$, and $0.20 \mu \mathrm{mol} \mathrm{L}^{-1}$ ) concentration of 3-MPA using derivatization withmonobromobimane.

Figure 3 -Net 3-MPA fluxes (concentration change over 4 hours of incubation)in sediment slurry samples from the Douro Estuary (muddy, sandy and fine sediment and rocky biofilm slurries)underoxic conditions. 


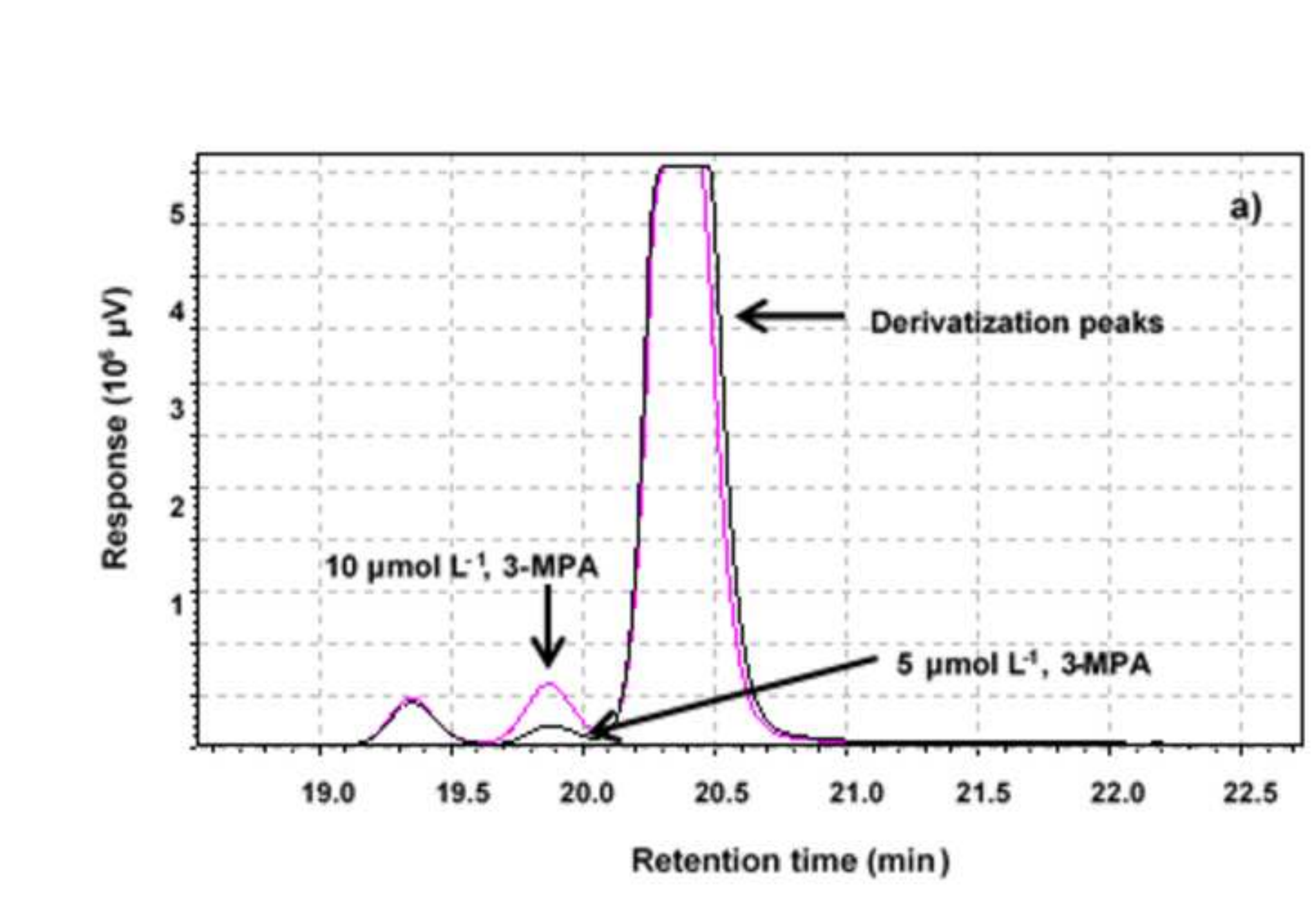

(1)

\begin{abstract}
(1)
\end{abstract}

(1)
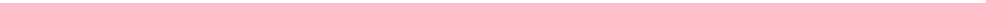


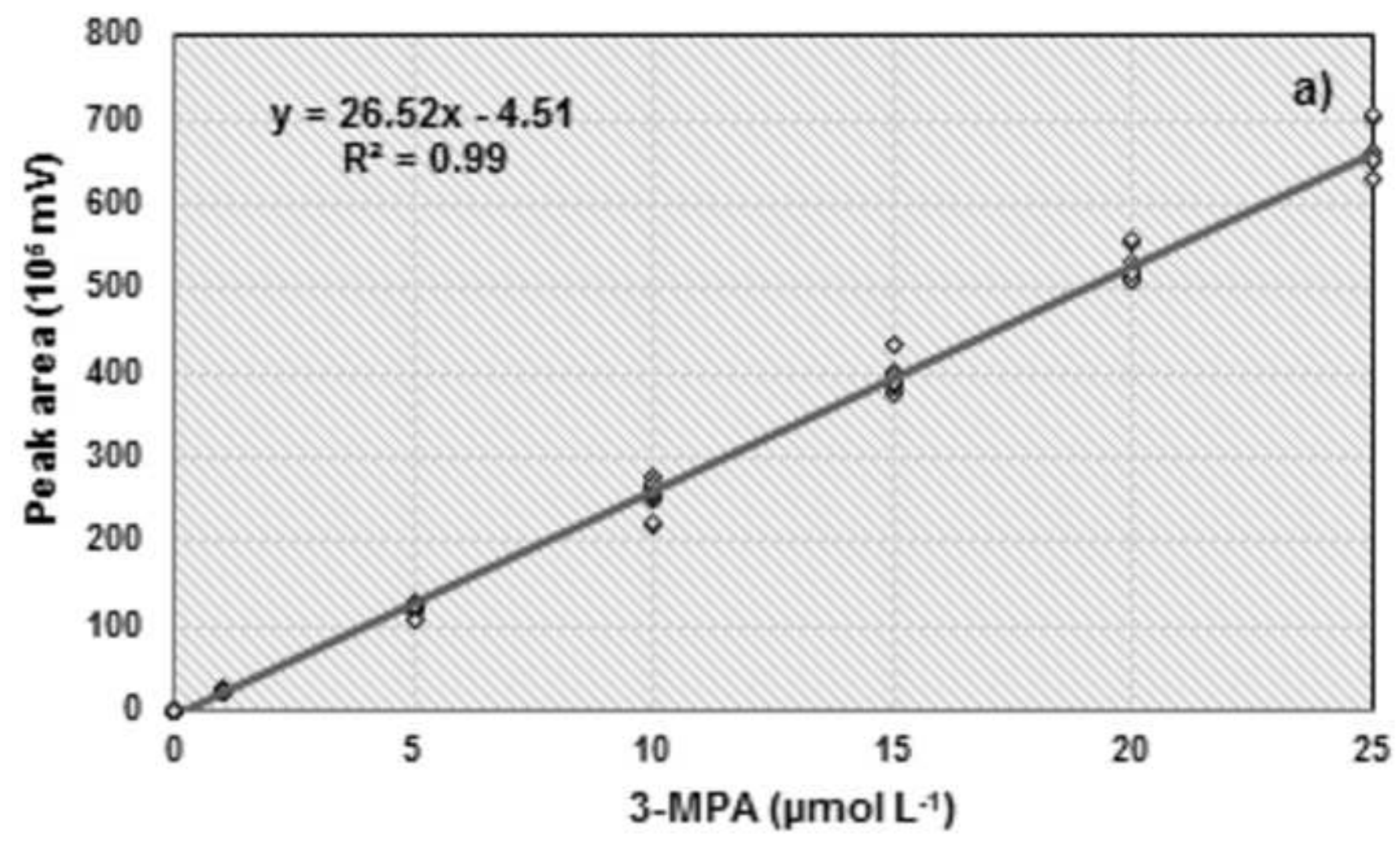




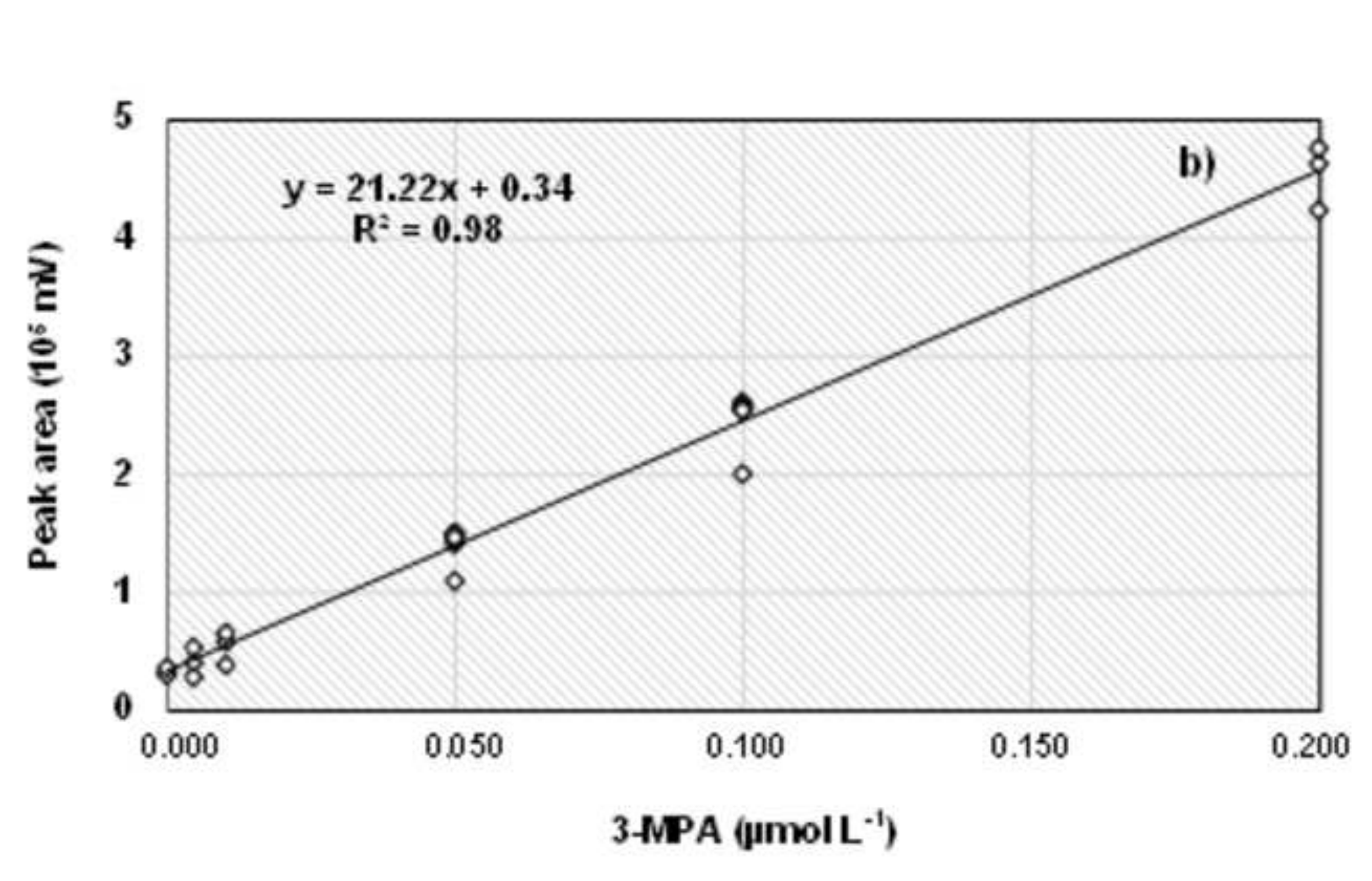




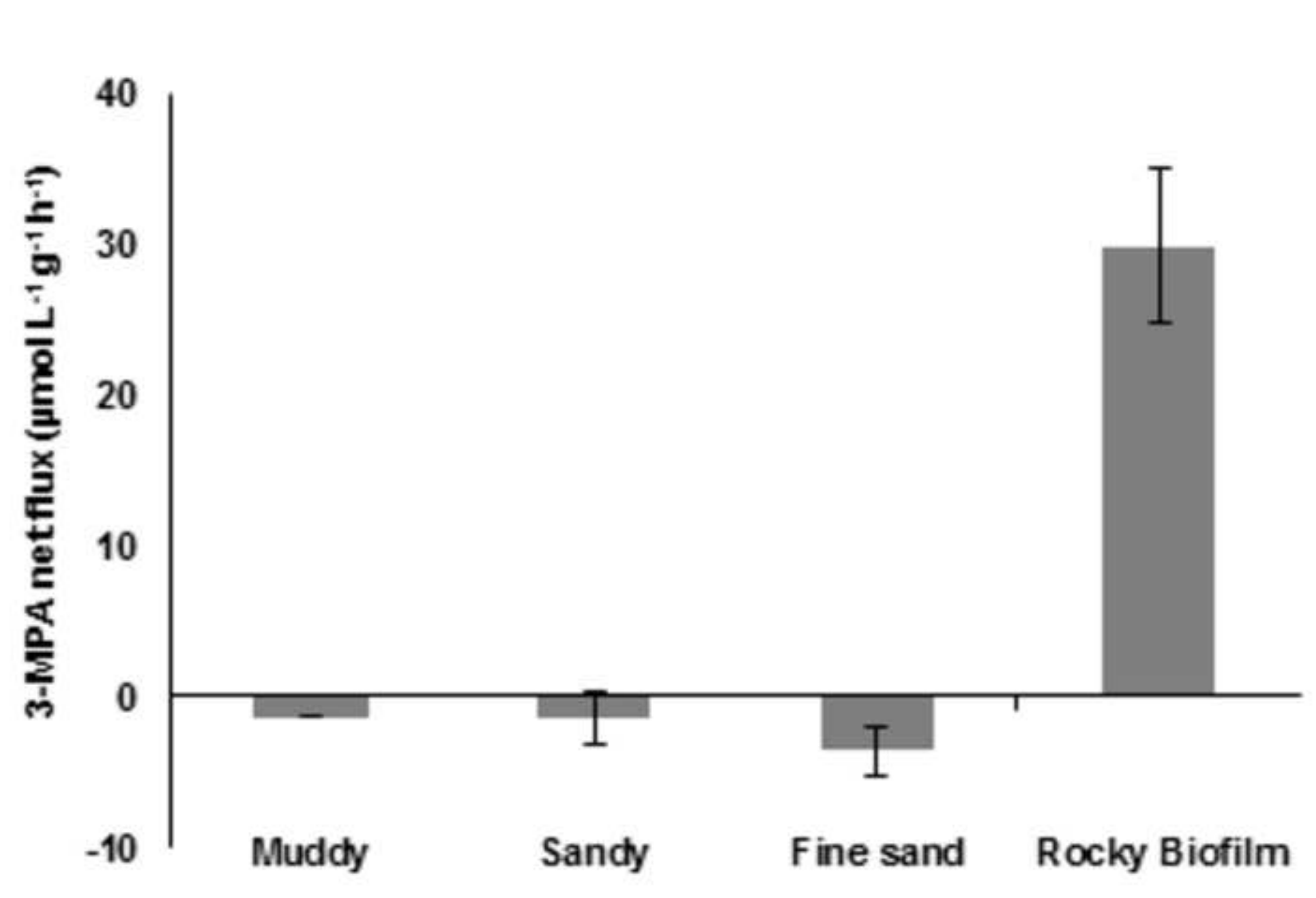




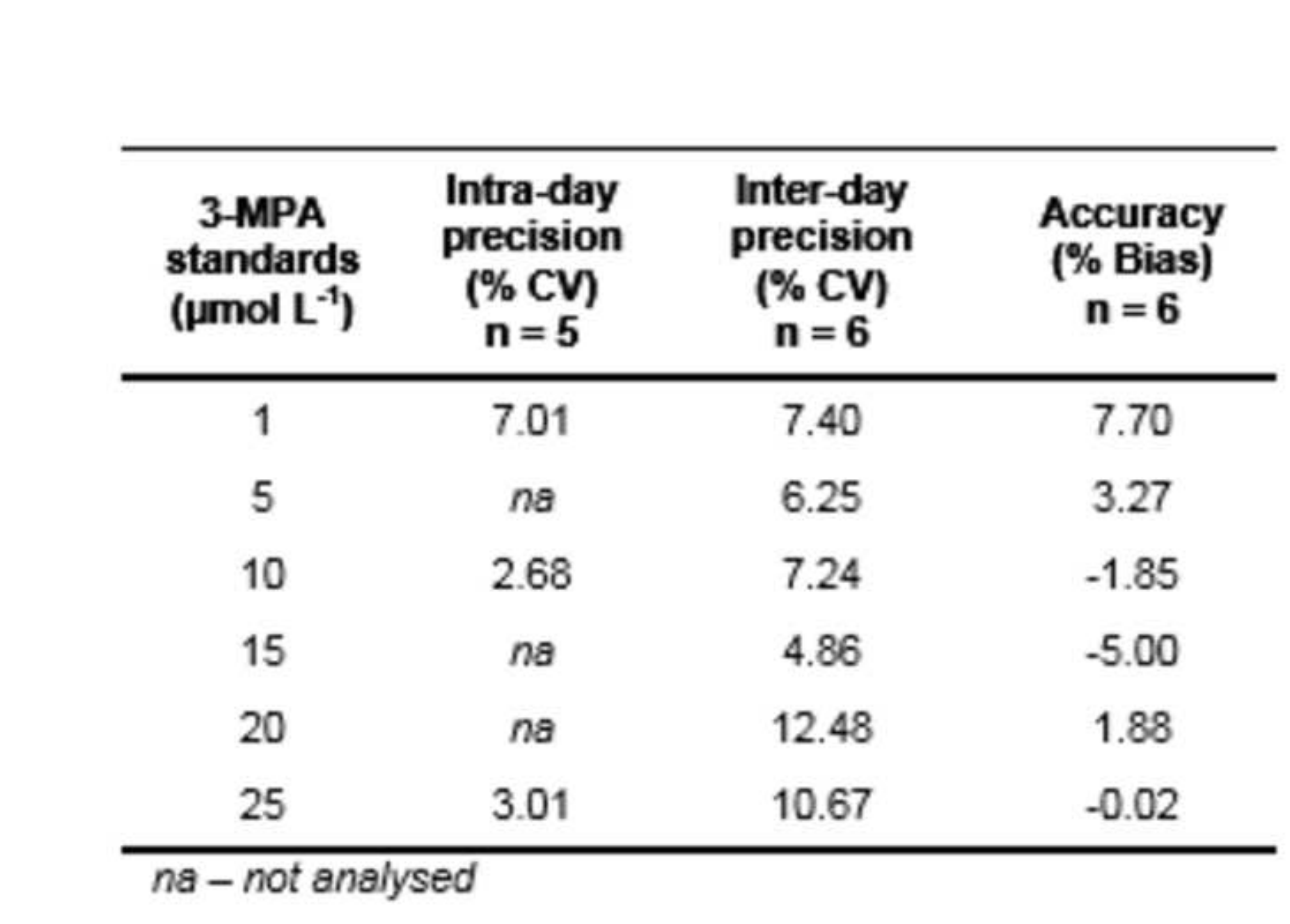

standards

( $\mathrm{\mu} \mathrm{mol} \mathrm{L} \mathrm{L}^{-1}$ )
Intra-day precision

(\% CV)

$$
\mathrm{n}=\mathbf{5}
$$

Inter-day

precision

(\% CV)

$\mathbf{n}=\mathbf{6}$
Accuracy

\% Bias)

$\mathbf{n}=\mathbf{6}$

\begin{tabular}{|c|c|c|c|}
\hline $\begin{array}{c}\text { 3-MPA } \\
\text { standards } \\
\left.(\mu \mathrm{mol} \mathrm{L})^{-1}\right)\end{array}$ & $\begin{array}{c}\text { Intra-day } \\
\text { precision } \\
(\% \mathrm{CV}) \\
n=5\end{array}$ & $\begin{array}{c}\text { Inter-day } \\
\text { precision } \\
(\% \mathrm{CV}) \\
\mathbf{n}=\mathbf{6}\end{array}$ & $\begin{array}{c}\text { Accuracy } \\
\text { (\% Bias) } \\
n=6\end{array}$ \\
\hline 1 & 7.01 & 7.40 & 7.70 \\
\hline 5 & na & 6.25 & 3.27 \\
\hline 10 & 2.68 & 7.24 & -1.85 \\
\hline 15 & no & 4.86 & -5.00 \\
\hline 20 & na & 12.48 & 1.88 \\
\hline 25 & 3.01 & 10.67 & -0.02 \\
\hline
\end{tabular}


Concentration 3-MPA Water salinity Recovery RSD $\left(\mu \mathrm{mol} \mathrm{L}^{-1}\right)$

(ppt)

(\%)

(\%)

\begin{tabular}{cccc}
\hline \hline 1 & & 104 & 0.8 \\
5 & 0.17 & 105 & 0.2 \\
10 & & 98 & 6 \\
20 & & 99 & 1 \\
\hline 1 & & 97 & 3 \\
5 & 35.85 & 102 & 0.5 \\
10 & & 99 & 0.3 \\
20 & & 98 & 0.6 \\
\hline
\end{tabular}


Storage time

\begin{tabular}{|c|c|c|c|c|c|c|}
\hline & \multicolumn{6}{|c|}{ Storage time } \\
\hline & $\begin{array}{c}1 \\
\text { days } \\
\end{array}$ & $\begin{array}{c}2 \\
\text { days }\end{array}$ & $\begin{array}{c}1 \\
\text { week }\end{array}$ & $\begin{array}{c}2 \\
\text { weeks }\end{array}$ & $\begin{array}{c}2 \\
\text { months }\end{array}$ & $\begin{array}{c}1 \\
\text { year }\end{array}$ \\
\hline $5 \mu \mathrm{mol} \mathrm{L-1}, 3-M P A$ & 100 & 99 & 99 & 100 & 98 & 95 \\
\hline $10 \mu \mathrm{mol} \mathrm{L-1}, 3-M P A$ & 100 & 98 & 99 & 100 & 108 & 97 \\
\hline $25 \mu \mathrm{mol} \mathrm{L} L^{-1}, 3-M P A$ & 100 & 98 & 99 & 100 & 108 & 98 \\
\hline
\end{tabular}

